\title{
MAKNA BUDAYA MINANGKABAU DALAM FILM SALISIAH ADAIK
}

\author{
Hendarti Darmawan $^{1 *}$, Dede Pramayoza ${ }^{2 *}$ Yus ril $^{3 *}$ \\ Penciptaan dan Pengkajian Seni, Program Pascasarjana \\ Institut Seni Indonesia Padangpanjang \\ Jl. Bahder Johan, Guguak Malintang, Padangpanjang, Kota Padangpanjang, 27126. \\ Sumatera Barat. Indonesia \\ Email:hendartidarmawan@gmail.com,dedepramayoza.neo@gmail.com,yusril2001@gmail.com
}

\begin{abstract}
Abstrak
Film Salisiah Adaik merupakan film independen Sumatera Barat yang bertemakan budaya Minangkabau. Film ini menceritakan tentang perselisihan adat pernikahan antara daerah Pariaman dan Payakumbuh yang dikemas dalam bentuk fiksi dengan gaya artistik yang detail dan khas sehingga memiliki nilai estetik. Estetika film Salisiah Adaik telah melahirkan makna dan arti budaya itu sendiri, untuk mengungkapkan makna tersebut dilakukan dengan analisa estetika formalisme Sergei Eisenstein. Setiap adegan dapat menggambarkan dan mengungkapkan makna budaya Minangkabau sepertikedamaian, keramahan masyarakat Minangkabau dan keteguhan masyarakat Minangkabau dalam menjunjung tinggi tradisi daerah masing-masing sesuai dengan pepatah Minangkabau lain lubuak lain ikaannyo, lain ladang lain ilalang (lain lubuk lain ikannya, lain ladang lain ilalang.
\end{abstract}

Kata Kunci: salisiah adaik, makna budaya minangkabau .

\begin{abstract}
Salisiah Adaik is an independent West Sumatrafilm with a Minangkabau culture theme. This film tells about a marriage custom dispute between the Pariaman and Payakumbuh areas which is packaged in fiction with a detailed and distinctive artistic style that hasaesthetic value. The aesthetics of the film Salisiah Adaik has given birth to the meaning and meaning of the culture itself, to express the meaning is done with aesthetic analysis of Sergei Eisenstein's formalism. Each scene can depict and express Minangkabau cultural meanings such as peace, friendliness of the Minangkabau people and the determination of the Minangkabaupeople in upholding the traditions of their respective regions in accordance with the Minangkabau proverb, another lubuak ikaannyo, another field of grass that is different (another bottom of the fish, another field of reeds.
\end{abstract}

Keywords: salisiah adaik, makna budaya minangkabau.

\section{PENDAHULUAN}

Mempelajaribentuk sebuah karya seni sama dengan melakukan sebuah studiestetika. Begitu juga dengan mempelajari bentuk film, maka sama dengan melakukan studi estetika film. Hal ini didukung dengan pernyataan, bahwa estetika merupakan refleksi atas fenomena makna yang dianggap sebagai sebuah fenomena artis tik (Aumont, Bergala, Marie, \& Vernet, 1992). Berdas arkan pernyataan tersebut maka estetika merupakan sebuah studi tentang makna yang kemudian dianggap sebagai sebuah pesan artis tik yang muncul pada sebuah karya seni.

Pada tahun 1958, teori estetika film terbentuk menjadi polaris asidua paradigma besar yaitu teori formalis me dan realisme. Teori formalis melihat film dari konstruksi dan komposisi film, sedangkan teori realis melihat film berdasarkan kemampuan film untuk menawarkan sebuah pandangan yang tak terjangkau atau realitas yang tidak termediasi. Dengan kata lain, formalis berfokus padaartifisial film, sedangkan realis berfokus pada semi transparansi media filmis, yang seolah-olah membawa penonton menjadi saksi langsung.

Film Salisiah Adaik merupakan sebuah karya film independen Sumatera Barat yang disutradarai oleh Ferdinand Almi. Film ini yang mengungkap perjalanan manis pahitnya tradisi di Minangkabau, yang bercerita tentang tradisi pernikahan yang saling bertolakbelakang antara adat Pariaman dengan adat Payakumbuh, sehingga hal tersebut menjadi konflik utama yang dihadapi oleh Muslim dan Ros selaku tokoh utama dengan latar tahun 1950an dengan gaya artistik yang khas dan detail, gaya artistik dan kekhas an tersebut tidak terlepas dari dukungan media pendukung dalamproses pembuatan filem ini, dimana media merupakan segala hal yang dapat digunakan untuk menyalurkan pesan, informasi, knowledge, dan lain sebagainya (Kartono, 2020: 128). Bantuan media 
seperti lighting, kostum, dan lain sebagainya, inilah yang membuat suasana atau keadaan film menjadi hidup dan seolah-olah penonton kembali kondisi film ters ebut.

Berdas arkan beberapa adegan yang memperlihatkan persoalan budayaMinangkabau didalamfilm Salisiah Adaik telah melahirkan suatu makna dan arti dari budaya itu sendiri. Ada makna dari representasi budaya Minangkabau yang dibentuk s ecara tidak s adar melalui interaksi para tokoh di dalam film melalui elemen-elemen medium film tersebut yang dianalis a berdasarkan seni dan keindahan di dalam film itu sendiri. Melalui film Salisiah Adaik, Ferdinand Almi selaku sutradara mengundang penonton untuk menggunakan imajinasinya dengan harapan bahwa penonton dapat menciptakan pengalaman sendiri atas cerita yang disampaikan melalui filmnya.

Untuk mengetahui estetika formalis film Salisiah Adaik diperlukan analis is estetika formalis me Sergei Eisenstein. Tulisan ini membahas makna dari film SalisiahAdaik berdas arkan teori es tetika formalis me Sergei Eisenstein dari beberapa adegan yang telah penulis pilih sesuai tingkat dramatik film yang merepresentasikan budaya Minangkabau.

\section{KAJIAN TEORI}

Kajian teori dalam tulisan ini adalah kajian estetika film Salisiah Adaik untuk mengungkapkan makna film dalam merepres entasikan budaya Minangkabau dengan pendekatan estetika formalisme Sergei Eisenstein. Estetika adalah teori-teori yang mencakup penyelidikkan tentang yang indah, penyelidikkan tentang prinsip-prinsip landasan seni, pengalaman yang berkaitan dengan seni, penciptaan seni, penilaian atau refleksiterhadap karya seni (Ali, 2003:2). Menurut Aumont, estetika merupakan refleksi atas fenomena makna yang dianggap sebagai sebuah fenomena artis tik (Aumont, Bergala, Marie, \&Vernet, 1992). Ketika mempelajari bentuk sebuah karya seni sama dengan melakukan sebuah studi estetika. Begitu jugadengan mempelajari bentuk film, maka sama dengan melakukan studi estetika film. Es tetika film adalah studi film sebagai sebuah seni dan sebagai sebuah pesan artistik (Aumont et al., 1992). Berdasarkan pernyataan tersebut dapat disimpulkan bahwa estetika film merupakan pengungkapan makna di dalam serangkaian adegan dari awal sampai akhir yang bertujuan untuk menyampaikan pesan kepada penikmat atau penonton film sehingga makna-makna yang muncul secara eks plis it dan implicit dianggap sebagai sebuah pesan artistik.
Gorga : Jurnal Seni Rupa

Volume 09 Nomor 01 Januari-Juni 2020

p-ISSN: 2301-5942 | e-ISSN: 2580-2380

Menurut Warrent Bucklund (2015) di dalam bukunya menyatakan bahwa untuk mengungkapkan makna di dalam film dengan pendekatan estetika film maka Sergei Eisenstein dan kaum montage-Soviet jawabannya ada pada montase dan sinematik. Sinematik terbagi berdasarkan Mise en scene, sinematografi dan suara (Bordwell \& Thompson, 1950). Menurut Ferdinand de Saususure, berpendapat bahwa makna merupakan konsep yang dimiliki oleh suatu tanda linguistik. Sedangkan menurut Homby menjelaskan bahwa makna merupakan apa yang kita artikan atau dimaksudkan oleh kita. Berdasarkan pernyataan tersebut, dapat disimpulkan bahwa makna di dalam film merupakan sebuah pesan yang dapat dirasakan dan dipahami maksud yang terdapat didalam film melalui pengalaman penonton yang kemudian dapat dis ampaikan secara linguistik.

\section{METODE PENELITIAN}

Metode penelitian ini dilakukan melalui metode kualitatif dengan pendekatan film studies dengan kajian utama pada estetika formalisme Sergei Eis enstein. Penelitian ini sangat menekankan tentang keindahan, pesan artistik, pengalaman pribadi dan interpretasi budaya Minangkabau oleh sutradara. Fokus penelitian ini meliputi telaah dokumen berupa karya film Salisiah Adaik, study pustaka dan wawancara. Melalui metode ini akan diperoleh hasil berupa makna di dalam film Salisiah Adaik.

Penelitian ini dilakukan dengan pendekatan mentelaah dokumen karya audiovisual Salisiah Adaik dan penulis memilih beberapa adegan yang mendukung dramatik di dalam film ini. Penelitian ini penulis fokuskan juga pada aspek budaya Minangkabau dan tradisi yang dilakukan masyarakat di daerah Pariaman dan Payakumbuh dengan pandangan estetika formalis me Sergei Eis enstein.

\section{HASIL DAN PEMBAHASAN}

\section{Hasil}

Hasil penelitian ini memusatkan kajian pada makna film Salisiah Adaik sebagai interpretasi sutradara Ferdinand Almi dalam merepresentasikan budaya Minangkabau yang dikaji melalui estetika formalisme Sergei Eisenstein. Film Salisiah Adaik ini memiliki makna yang berbeda-bedapada setiap adegannya yang mengungkapkan tradisi dan budaya Minangkabau berdasarkan pepatahnya lain lubuak lain ikannyo, lain ladang lain ilalang (lain lubuk lain ikannya, lain ladang lain ilalang) maksudnya bahwa setiap daerah memiliki budaya dan tradisi yang berbeda-beda sehingga memiliki makna yang berbeda pula. 


\section{1). Estetika Formalisme Sergei Eis enstein}

Melalui es tetika film dapat diketahui bahwa teori-teori film dan pendekatan film diklasifikasikan menjadi dua, namun dalam pembahasan ini penulis menggunakan teori estetika Formalisme Sergei Eisenstein karena penulis menganalis a film Salisiah Adaik dari khas dan kedetailan artistik yang disuguhkan oleh sutradara dalam membentuk makna. Teori formalis melihat film dari konstruksi dan komposisi film, formalis berfokus pada artifisial film. (Elsaesser \& Hagener, 2010). Menurut Sergei Eisenstein, untuk melihat nilai estetik pada sebuah film dapat dilihat dari medium film itu sendiri berupa Mise En Scene, Sinematografi, Montase dan Suara.

\section{(1). Mise En Scene}

Sergei Eisenstein menyebutnya sebagai sebuah kelahiran dari konsep mise-en-cadre, yaitu komposisi gambar dari shot-shot yang saling terkait dalam sebuah urutan montase. Pada pertunjukan teater, konsep mise-en-cadre disebut dengan konsep mise-enscene. yaitu hubungan timbal balik dari orang-orang dalam aksinya atau dalampermainannya. Selanjutnya, penyebutan mise-en-cadre lebih dikenal secara umum dalam istilah film sebagai mise-en-scene (Eisenstein, 1957:16). Mise-en-scene meliputi pula aspek-aspek: setting, kostum dan tata rias, pencahayaan dan pergerakan pemain (Bordwell \& Thompson, 1950).

\section{(2). Sinematografi}

Sinematografi dalam setiap shot yang diambil oleh kamera juga sangat diperhatikan. Fillmmaker tidak hanya berbicara tentang film apa yang dibuat tetapi bagaimana seorang filmmaker membuat film. Sehingga, sinematografi pada setiap shot film sangat diperhatikan.

\section{(3). Montase}

Montase merupakan teori yang paling krusial dari teori-teori lain. Hal ini dikarenakan dalam teori montase merupakan teknik penggabungan dan penyusunan elemen seperti gambar, suara, grafik sehingga menjadi satu kes atuan yang utuh dalam film.

\section{(4). Suara}

Suara adalah teknik film yang kuat karena beberapa alasan. Untuk satu hal, yakni membentuk rasa yang berbeda. Sergei Eis enstein menyebutnya "sinkronisasi indra" membuat sebuah irama atau kualitas ekspresif menyatukan gambar dan suara. Selain itu, suara dapat membentuk cara kita memandang dan menafsirkan gambar (Bordwell \& Thompson, 1950).

\section{Pembahasan}

Makna yang terkandung dalamfilm Salisiah Adaik ini adalah kedamaian, ketenangan dan keramahan masyarakat Minangkabau serta makna konflik perselisihan adat Pariaman dan Pakumbuh yang menjadi penghalang hubung an Ros dan Muslim selaku tokoh utama didalamfilm ini. Makna tersebut penulis dapatkan melalui analis a dari beberapa adegan yang telah penulis pilih berdasarkan tingkat dramatiknya. Dibawah ini merupakan pembahasan dari dua adegan yang penulis pilih dalam mengungkapkan makna budaya Minangkabau dari film Salisiah Adaik sebagai berikut:

1). Mengungkap Makna Film Salisiah Adaik Berdasarkan Analisa Estetika Formalisme Sergei Eisenstein

\section{(1). Adegan Pengantar Film Salisiah Adaik (Tesis)}

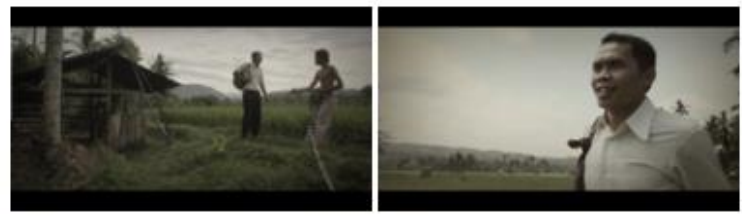

Gambar 1. Adegan Pengantar Film Salisiah Adaik (Sumber: Capture film Salisiah Adaik timecode 00.00.31-00.03.01, 2020)

\section{a. Deskripsi Adegan}

Adegan pengantar film Salisiah Adaik secara garis besar memiliki struktur atau komposisi film sebagai berikut: Suara saluang menjadi pembuka adegan yang memperlihatkan pemandangan alam dan seekor kerbau, lalu mengiringi adegan Mus lim yang berjalan melewati persawahan dan berpas-pasan dengan seorang laki-laki. Mereka berdialog singkat memberikan informasitentang keberangkatan Muslim ke Payakumbuh.

\section{b. Analisis}

\section{a). Mise En Scene}

Setting : Setting pada pembuka adegan memperlihatkan pemandangan sawah berjenjang dan alam yang tenang dan sepi. Ketenangan divisualis asikan melalui tempat-tempat yang tidak ada keramaian yang tampak selain jalan setapak persawahan dan hanya ada Muslim yang berjalan sendiri lalu bertemu dengan seorang laki-laki yang bekerja sebagai tukang baruak (pengambil kelapa dengan jasa kera). Bahasa yang mereka gunakan adalah bahasa Minangkabau terkhusus berdialek Pariaman. Suasana yang dihadirkan menggambarkan 
ketenangan alam dan keramahan masyarakat Minangkabau.

Tata Rias dan Kostum : Kostum tokoh Muslim mengenakan kemeja berwarna cream yang dimasukan bagian bawah baju ke dalam celana coklat tua model lama serta sendal jepit, di lengannya terlihat sedang menyandang sebuah kain sarung yang dijadikan tas untuk membawa pakaian. Make up tokoh Muslim dibuat senatural mungkin seperti kehidupan seharihari. Melalui model kostum Muslim, dapat diketahui karakter tokoh Muslim, yakni ramah, sederhana, jujur, rapi, wibawa dan mudah bergaul.

Pencahayaan: Pencahayaan pada serangkaian adegan di atas menggunakan pencahayaan yang natural. Artinya, memanfaatkan sinar matahari langsung sehingga adegan tampak natural. Bayangan yang terbentuk pada serangkaian adegan tokoh Muslim tidak terlihat keras atau tajam seperti ketika matahari bersinar terang. Situasi yang ada pada serangkaian adegan adalah situasi yang tenang dan menunjukkan waktu pada sore hari.

Pemain serta pergerakannya : Muslim berjalan menyu suri jalan setapak persawahan dengan eks presi semangat dan bertegur sapa dengan orang lain yang ditafsirkan sebagai Muslim adalah orang yang ramah dan mudah bersosialisasi. Ges tur Muslims aat berjalan menunjukkan kepribadian muslim yang tegas dan menghargai orang lain.

\section{b). Sinematografi}

Shot awal, kamera bergerak secara tiltdown pelan. Pergerakan kamera dari atas ke bawah sangat halus. Hal ini menunjukan kepada penonton bahwa langit pada saat itu dalam keadaan mendung dan tenang yang menunjukkan waktu sore menjelang senja. Kamera bergerak ke bawah hinggaberada pada pos is $\mathrm{i}$ seperti mata memandang pada umumnya (straight on angle). Motivasi dari shot ini adalah untuk menunjukkan latar belakang tempat dimana tokoh Muslim berasal dan suasana tempat itu. Setelah itu terlihat shot Medium Close Up wajah muslim yang memperlihatkan eks presi s emangat Muslimyang akan berangkat ke Payakumbuh dan sebagai perkenalan tokoh Muslim.

\section{c). Montase}

Antara shot pertama sampai shot terakhir dalam adegan pembuka ini diberikan transisi cut. Motivasi transisi yang diberikan antara shot pertama sampai shot ketujuh adalah menunjukkan kelanjutan atau kontinuitas shot. Benturan antar-shot membangun suasana, yakni ketenangan, dan kedamaian. Konflik
Gorga : Jurnal Seni Rupa

Volume 09 Nomor 01 Januari-Juni 2020

p-ISSN: 2301-5942 | e-ISSN: 2580-2380

y ang dibangun di dalams erangkaian shot yakni daerah yang masih asri tanpa ada banyak campur tangan manusia dan teknologi, namun hal itu menjadi positivitas bagi Muslim. Benturan seluruh shot membangun sebab dan akibat dari perjalanan Mus lim dari Pariaman ke Payakumbuh dan memberikan informasi-informasi tentang para tokoh secara berkesinambungan

\section{d). Suara}

Adegan diawali dengan musik tradisional Minangkabau yaitu bunyialat tiup saluang dan bansi mengiringi visual alam dan adegan. Musik saluang dan bansi inipun memberitahu penonoton tentang identitas dari latar belakang budaya tempat terjadi adegan tersebut yaitu budaya Minangkabau. Suas ana damai, tenang dan sepi tersebut pun membuat jelas suara jengkrik saat adegan di persawahan yang menandakan adegan terjadi waktu sore menjelang senja. Suara rerumputan yang terinjak kaki Mus lim s aat berjalan menyusuri jalan setapak di persawahan yang menandakan ketenangan dan keheningan.

Secara keseluruhan analisis di atas mulai dari pergerakan tokoh, posisi kamera, pencahayaan, serta suara mempengaruhi makna yang muncul dari serangkaian adegan pengantar. Ketidakadaan konflik dalam adegan, pergerakan kamera serta tokoh Mus lim yang berjalan dengan tenang dan ramah. Ambience suara jangkrik, musik saluang dan bansi serta dialog dan dialek membangun rasa nostalgia akan masa lampau daerah Minangkabau yang memberikan ketenangan, kes unyian serta kedamaian di tempat itu. Adegan awal sebagaiadegan pengantar film Salisiah Adaik mampu membangun suasana damai, hangat, asi dan tenang dalamadegan dan mengantarkan tentang kekayaan budaya Minangkabau.

\section{(2). Adegan Amak Ros Menentang Hubungan Ros dengan Muslim (Antitesis)}
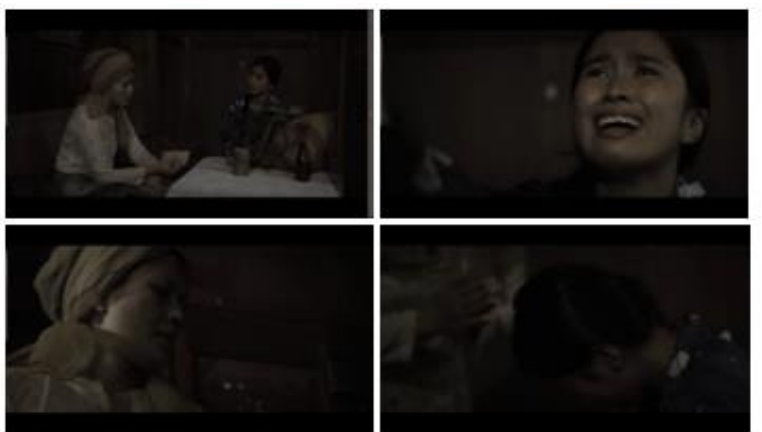

Gambar 2. Adegan Amak Menentang Hubungan Ros dengan Muslim 
(Sumber : Capture film Salisiah Adaik timecode 00.22.19-00.26.10, 2020)

\section{a. Deskripsi Adegan}

Tini (Ibu Ros) menunggu Ros di ruang tamu dengan memegang surat ditangannya. Ros masuk membawa sayuran didalamkeranjang belanjaannya dan duduk di dekat Tini. Tini mempertanyakan surat yang dia temui di kamar Ros. Tini senang karena dia merasa Ros sudah cukup umur untuk memikirkan hal yang demikian, Rospun tampak bahagia. Ketika Tini mengetahui pengirim Surat itu adalah Muslim dari Pariaman, spontan Tini marah dan menentang hubungan mereka karena adanya perselisihan adat antara adat Pariaman dan Payakumbuh. Ros menangis dan memohon kepada Tini, Tini tetap bersikeras dan memohon untuk Ros melupakan Mus lim. Tini masuk ke kamar meninggalkan Ros yang masih menangis.

\section{b. Analisis}

\section{a). Mise En Scene}

Setting : Adegan ini terjadi di dalam rumah Ros tepatnya di ruang tamu. Semua properti yang digunakan adalah peralatan rumah tanggapada zaman dahulu seperti meja kayu dan kursi jalin rotan yang memiliki ciri khas lengkungan pada lengan kursi. Diatas meja terlihat as bak yang terbuat dari potongan bambu dan lampu minyak yang menggunakan botol kaca kecil. Dinding-dinding kayu dan tiang diruangan ters ebut tampak rapuh. Dari setting dan properti pada adegan inidapat ditafsirkan sebagai informasi status ekonomi keluarga Ros yang kurang mampu pada kisaran tahun lampau karena belum adanya perlatan rumah tangga y ang berupa elektronik maupun hias anhias an ruangan yang modern.

Tata Rias dan Kostum: Tokoh Ros mengenakan dress pendek selutut berlengan panjang yang berwarna biru tua dengan motif daun berwarna putih. Tata rias Ros natural seperti keadaan sehari-hari dengan rambut berkepang satu dan tanpa pernah pernik perhiasan. Warna biru tua yang dikenakan oleh Ros dapat ditafsirkan sebagai suasana hati Ros yang menunjukkan ketegasan. Warna gelap dari biru tua ters ebut juga menambah ras a ketertekanan Ros. Tokoh Tini mengenakan kostum baju kuruang basiba berwarna cream dengan bawahan batik bunga-bunga yang juga berwarna cream. Hiasan kepala Tini mengenakan tingkuluak yaitu selendang berwarna coklat kekuningan yang dililitan ke kepala untuk menutupi rambut. Darikostumdan tata rias tokoh Tini dapat ditafsirkan sebagai tokoh orang tua Minangkabau yang sopan dan bertanggung jawab yang menjujung tinggi adat dan agama, hal ini dilihat dari cara berpakaian Tini serta makna dari tingkuluak
Gorga : Jurnal Seni Rupa

Volume 09 Nomor 01 Januari-Juni 2020

p-ISSN: 2301-5942 | e-ISSN: 2580-2380

yang dia gunakan yang ditinjau berdasarkan pada masa itu.

Pencahayaan : Pencahayaan pada adegan ini menggunakan pencahayaan yang membangun mood para tokoh. Pencayaan low light menekankan suas ana hati Ros yang juga dapat mempengaruhi mood penonton. Selain itu, pencahayaan ini juga menambah kesan atau karakter pada film ini yaitu kesan klasik Minangkabau yang identik dengan warna-warna kuning.

Pemain dan Pergerakannya:Tokoh Tini hanya duduk dis ebuah kursi jalin rotan dengan gestur menggoyang goyangkantangan kanannya yang memegang surat. Tini menanyakan surat, Gestur Ros langsung merapatkan posisi duduknya dan menundukkan kepalanya sangat dalam. Gerakan ini ditafsirkan sebagai rasa waspada dan ketakutan Ros jikalau Tini akan marah. Tatapan mata Ros yang memandang sendu ke arah Tini menginformasikan ketakutan dan seolah-olah Ros meminta ampun kepada Tini. Tini menyampaikan harapan-harapannya kepada Ros dan secara langsung menyatakan mendukung Ros jika ingin segera menikah. Ekspresi Ros tampak ters enyum bahagia terlihat dari gaya senyumnya yang memperlihatkan giginya dengan gestur yang mengangguk-anggukan kepala yang menginformasikan Ros setuju dengan semua yang dikatakan oleh Tini.

Ros menyebutkan Muslim adalah orang Pariaman, spontan Tini kaget dan menggeser duduknya kebelakang lalu lebih menaikkan nada suaranya yang ditafsirkan sebagai bentuk penolakan Tini terhadap Muslim. Posisi duduk Tini menjadi gelisah dan pergerakan tubuhnya lebih cepat. Ekspresi Ros langsung berubah dan menundukan kepalanya ketakutan. Ros berusaha lebih mencondongkan tubuhnya ke Tini dan memegang tangan Tini sambil menatap memohon kepada Tini. Tini semakin meninggikan nada suaranya dan lebih membusungkan dadanya lalu memukul meja lebih keras, ditafsirkan sebagai penolakan keras dan tegas oleh Tini terhadap hubungan Ros dan Muslim karena adanya perbedaan adat. Pergerakan tangan Tini mempertegas penolakannya. Tini berdiri dan membelakangi Ros .

\section{b). Sinematografi}

Shot pertama dalamadegan ini yaitu medium close up Tini dengan arah pandang eye level dan posisi Tini yang ada di sudut kiri layar. Shot kedua adalah knee shot Ros yang baru masuk ke dalam rumah dengan pengambilan long take yang mengikuti pergerakan Ros menuju tempat Tini hingga tampak Tini dan Ros 
yang duduk di kursi. Motivasi shot ini adalah memperlihatkan suasanadan ruangan tempat adegan ini terjadi serta menginformasikan keluas an ruangan ters ebut.

Shot ke tiga adalah medium close up Ros. Motivasi shot ini sebagai informasi segala eks presi dan gestur tubuh Ros saat adegan berlangsung yang lebih memberi tekanan pada emosional Ros dan mood adegan. Shot ke empat adalah medium close up Tini yang diambil secara following yaitu mengikuti segala pergerakan Tini. Motivasi shot ini membangun emosionalTini dengan pergerakan-pergerakan yang lebih cepat sehing ga lebih membangun sauana yang ribut atau heboh. Pada saat Tini berdiri, shot ini berubah arah pandang dari eye level menjadi low angle. Motivasi angle ini memberikan tekanan terhadap kekuatan dan kemarahan Tini yang menentang hubungan Ros dan Muslim.

Shot kelima adalah medium close up Ros dengan hight angle, yang juga memperlihatkan ketertekanan Ros pada situasi tersebut. Shot ke enam merupakan gambaran interaksi Tini yang memohon kepada Ros untuk melupakan Mus lim namun Ros tetap menolak dengan gesture menggeleng y ang diambil secara twoo shot dengan foreground keranjang belanja Ros. Motivasi dari shot-shot dalamadegan ini adalah untuk mempertegas semua ekspresi tokoh untuk membangun mood penonton dan sebagai awal permasalahan terjadi.

\section{c). Montase}

Berdas arkan deskripsi pada seluruh adegan ini, dapat diinformasikan bahwa pada shot pertama hingga shot ke enammerupakan gambaran suasana dan eks presi dari tokoh Tini dan Ros yang digabungan secara bergantian sehingga membangun situasi dan mengantarkan para tokoh kepada permasalahan yang terjadi. Susunan dari shot-shot ini menjadi sebuah kontinuitas adegan secara linear.

Shot pertama dan shot ke tiga merupakan tesis pers oalan harapan-harapan Tini kepada Ros yang telah menemukan jodoh untuk segera mempercepat niat baik ters ebut serta mengantarkan penonton pada kisah percintaan Ros dan Muslim yang baru dimulai. Ros sangat bahagia mendapatkan dukungan dari Tini selaku ibunya. Konflik terjadi ketika Tini mengetahui siapa laki-laki yang akan menikahi Ros tersebut.

Hal ini terlihat pada shot ke empat dan keenam sebagai antitesis. Tinibalik menentang hubungan Ros dan Muslimkarena persoalan adat mereka yang saling bertentangan. Ros hanya menangis mendengar
Gorga : Jurnal Seni Rupa

Volume 09 Nomor 01 Januari-Juni 2020

p-ISSN: 2301-5942 | e-ISSN: 2580-2380

penolakan keras dari Tini dan tetap mempertahankan keinginannya bersama Muslim. Tini dengan emosional menentang hubungan tersebut karena memikirkan keadaan keluarganya yang kurang mampu untuk membay ar adat Pariaman yang disebut dengan Bajapuik, selain itu Tini juga memikirkan bahwa hal tersebut akan menjadi beban besar bagi kaumnya untuk menjalankan adat Pariaman dan Payakumbuh yang sangat bertentangan.

Benturan dari shot pertama hingga shot keenam telah menghasilkan sintesis yaitu konflik yang terjadi terhadap hubungan percintaan Ros dan Muslim. Penghalang hubungan Ros dan Muslim bukanlah berasal dari orang lain yang tidak menginginkan mereka bersama, tetapi dari sistem adat mereka yang saling bertentangan. Sehingga Tini selaku ibu Ros memperingati Ros dengan hubungan mereka tersebut akan menjadi beban oleh kaumnya untuk memenuhi adat Pariamann. Pada daerah Pariaman dikenal dengan bajapuik yaitu memberikan sejumlah uang kepada Niniak Mamak (orang yang mengerti adat dan mengurus adat di Minangkabau) pihak laki-laki ketika ingin menjemput laki-laki tersebut untuk menikahi anak gadis dari pihak perempuan.

Sedangkan adat pernikahan Payakumbuh adalah maisi sasuduik yaitu pihak laki-laki harus memberikan sejumlah uang kepada pihak perempuan untuk keperluan membeli segala kebutuhan di kamar pengantin perempuan seperti membeli kasur, tempat tidur dan sebagainya. Sehingga dari masing-masing adat pernikahan tersebut dianggap sangat bertolak belakang dengan adat masing-masing dan menjadi pertentangan dalamhubungan Ros dan Muslim.

\section{d). Suara}

Pada shot pertama medium close up Tini hanya terdengar efek suara Ros membuka pintu dan Ros mengucapkan salam. Sound efek ini menginformasikan kepada penonton jika ada orang yang masuk ke dalamrumah sebelum shot berikutnya memperlihatkan Ros menutup pintu dan berjalan mendekati Tini. Pada adegan ini terdengar musik saluang yang membawa suasana dan pengharapan Tini kepada Ros. Musik ini juga membangun rasa cemas dan ketakutan Ros yang menyangkal Tini akan marah karena Ros mendapat surat dari seorang lakilaki. Saluang terdengar sepanjang Tini berdialog tentang dia menemukan surat tersebut di kamar Ros. Setelah itu tidak ada lagi terdengar musik latar. 
Kesan hening juga membangun suasana yang menegangkan ketika Tini menaikan nada suaranya yang diiringi dengen suara efek pergerakan tangan Tini yang menjelaskan persoalan, klimak dari kemarahan Tini pada saat dia memukul meja dengan keras. Suara efek keras Tini memukul meja juga diiringi musik latar Saluang dengan irama yang lebih cepat dari musik latar sebelumn ya. Musik latar berupa suara darialat musik saluang dan rabab dengan tempo yang cepat mengiringi Tini yang berbicara dengan cepat dan keras. Motivasi dari musik latar ini untuk membangun suasana yang menegangkan serta menyedihkan yang di alami oleh Ros sepanjang pertentangn antara Ros dan Tini berlangsung. Hingga saat Tini pergi meninggalkan Ros yang masih menangis, terdengarsuara ratapan yang membangun suasana lebih dramatis.

Berdas arkan analisis interpretas i pendekatan estetika formalis Sergei Eis enstein tersebut didapatkan sebuah makna konflik bahwa penghalang hubungan percintaan antara Ros dan Muslim bukanlah berdasarkan subjek atau tokoh lain, melainkan dari sistemadat pernikahan pada daerah masing-masing. Peristiwa ini telah tergambar pada pepatah Minangkabau yaitu "Lain lubuak lain ikannyo, lain ladang lain ilalang" (Lain lubuk lain ikannya, lain ladang lain ilalang) yang memiliki makna bahwa setiap daerah memiliki aturan adat dan tradisi yang berbeda-bedames kipun sama-s ama beras al dari suku Minangkabau.

\section{KESIMPULA DAN SARAN \\ 1.Kesimpulan}

Berdasarkan hasil dari analisa estetika film Salisiah Adaik didapatkesimpulan bahwa film Salisiah Adaik memiliki gaya artistik yang khas dan detail dalam merepresentasikan budaya Minangkabau. Kemudian adapun makna dari setiap adegan yang dibentuk oleh sutradara. Seperti pada beberapa adegan yang telah penulis pilih yaitu, pertama adalah serangkaian adegan pengantar film sebagai tesis ditemukan makna kedamaian, ketenangan dan keramahan masyarakat Minangkabau. Kedua adalah serangakaian penyebab terhalangnya hubungan Ros dan Muslim sebagai antites is, ditemukan makna konflik pers elisihan adat Pariaman dan Pakumbuh. Hasil dari analis is estetika formalisme Sergei Eisenstein film Salisiah Adaik adalah dapat diketahui makna yang tersembunyi dibalik rangkaian adegan-adegan film Salisiah Adaik. Adapun makna yang ada dibalik film Salisiah Adaik adalah makna kedamaian, keramahan dan makna konflik atau penghalang hubungan Ros dan Muslim karena sistem adat mereka yang berbeda.
Gorga : Jurnal Seni Rupa

Volume 09 Nomor 01 Januari-Juni 2020

p-ISSN: 2301-5942 | e-ISSN: 2580-2380

\section{Saran}

Hasil dari penelitian film Salisiah Adaik Sutradara Ferdinand Almi tentunya masih banyak kekurangan dan masih belums empurna, sehingga disarankan bagi peneliti berikutnya untuk menelitinya lebih secara mendalam yang dikaji dari semua disiplin ilmu (multi disiplin). Kemudian diharapkan kepada penonton untuk tidak mudah menjustifikasi film tanpa terlebih dahulu mendalami makna dari film tersebut. Film-film daerah yang mengangkat tema budaya sebaiknya lebih disebarluaskan lagi kemasyarakat, karena melalui media film kita dapat melestarikan budaya dan memperkenalkan budayakepada generasi selanjutnya.

\section{DAFTAR RUJUKAN}

Ali, M. (2003). Estetika, Pengantar Filsafat Seni. Jakarta: Sanggar Luxor.

Aumont, J., Bergala, A., Marie, M., \& Vernet, M. (1992). Aesthetics of Film. USA: University of Texas Press.

Bordwell, D., \& Thompson, K. (1950). Film Art, An Introduction (8th ed.). New York: The McGraw-Hill.

Eisenstein. (1957). Film Form and The Film Sense. USA: Meredian Books.

Els aes ser, T., \& Hagener, M. (2010). Film Theory, An Introduction Through The Senses. New York: Routledge.

Kartono, G., Mesra, M., \& Azis, A.C. K. pengembangan media Ajar Grafis Komputer MateriWPAP dalamBentukE-book dan Video Tutorial bagi Mahasiswa Seni Rupa. Gorga: Jurnal Seni Rupa, 9(1), 127-132.

Warrent Buckland. (2015). Film Studies An Introduction. London: Oxford Brookes University. 